\title{
The Role of Anxiety and Adaptation to Illness in the Intensity of Postchemotherapy Nausea in Cancer Patients
}

\author{
Tomás Blasco \\ Autonomous University of Barcelona \\ Carmen Alonso \\ Hospital of Santa Creu i Sant Pau
}

\author{
Cinta Pallarés \\ Hospital of Santa Creu i Sant Pau \\ Juan José López López \\ Hospital of Santa Creu i Sant Pau
}

\begin{abstract}
The aim of this work was to assess whether cancer patients presenting high anxiety levels or poor adaptation to cancer experience higher levels of postchemotherapy nausea, regardless of the emetogenicity of the chemotherapy schedule. Sixty-three patients were interviewed before receiving their chemotherapy schedule and some psychological variables were assessed. Nausea intensity was also assessed after treatment. The results showed that patients with relatively higher levels of nausea reported higher levels of anxiety prior to chemotherapy and lower levels of adaptation to cancer. Thus, evidence for a modulating effect of psychological factors in postchemotherapy emesis is suggested.

Key words: chemotherapy, nausea, anxiety, adlaptation to illness
\end{abstract}

El objetivo del presente trabajo fue evaluar si los pacientes de cáncer que muestran altos niveles de ansiedad o una escasa adaptación a la enfermedad experimentan también una elevada náusea postquimioterapia independientemente del potencial emetizante del tratamiento. Se entrevistó a 63 pacientes antes de que recibieran uno de los ciclos de quimioterapia y se evaluaron diferentes variables psicológicas. Asimismo, se registró la intensidad de náusea postratamiento. Los resultados indican que los pacientes con mayores niveles de náusea muestran unos niveles de ansiedad previos a la quimioterapia más elevados y unos niveles de adaptación al cáncer más bajos. Se sugiere la posibilidad de que los factores psicológicos tengan un efecto modulador de la intensidad de la náusea postquimioterapia.

Palabras clave: quimioterapia, náusea, ansiedad, adaptación a la enfermedad

This study was supported by DGICYT Grant PB97-0212 from the Ministerio de Educación y Ciencia, Madrid (SPAIN).

We wish to thank Nuria Inglés for her valuable contribution to this study, as well as Dr. Alberto Fernández-Teruel for his constructive comments on earlier drafts of this manuscript, and Dr. M. Carme Viladrich for her assistance with the statistical analyses.

Correspondence concerning this article should be addressed to Tomás Blasco, Área de Psicologia Bàsica. Apartado 29. Universitat Aucònoma de Barcelona. 08193 Bellatera (Barcelona), Spain. Fax: 349358133 29. E-mail: tomas.blasco@uab.es 
Nausea and vomiting are amongst the most distressful side effects of chemotherapy in cancer patients (Burish \& Carey, 1986; Coates, 1986; Gralla, 1987; Love, Leventhal, Easterling, \& Nerenz, 1989). However, nausea and vomiting after chemotherapy are not the only emetic side effects associated with that treatment. In fact, $25 \%$ of patients experience a phenomenon called "anticipatory nausea and vomiting," which is observed when some patients exhibit nausea and vomiting before chemotherapy is administered (Blasco, 1994; Redd, Burish, \& Andrykowski, 1985).

Clinical psychologists have devoted their main efforts to finding out which factors are involved in anticipatory symptoms (Andrykowski, Redd, \& Hatfield, 1985; Carey \& Burish, 1988; Challis \& Stam, 1992; Hursti et al., 1994; Kvale et al., 1991; Morrow, Lindke, \& Black, 1991; Watson \& Marvell, 1992), as well as to reducing them through various therapies (Burish \& Tope, 1992; Carey \& Burish, 1988; Vasterling, Jenkins, Tope, \& Burish, 1993). Despite the extensive research carried out in this field, researchers have not yet gained complete knowledge about how, why, and in which patients, anticipatory nausea and vomiting appear.

In order to extend the scope of this knowledge, factors related with anticipatory nausea and vomiting, such as personality traits (Hursti et al., 1992) or individual differences in susceptibility to autonomic nervous system conditionability (Fredrikson et al., 1993; Kvale, Psychol, \& Hugdahl, 1994) have been considered. However, as has been suggested by Blasco (1994), because anticipatory symptoms do not usually appear without previous experience of postchemotherapy nausea and/or vomiting, these side effects seem to be one of the main factors in explaining the development of the anticipatory symptoms. Furthermore, psychological factors could modulate the intensity of postchemotherapy nausea and vomiting, as some studies have pointed out (Andrykowski \& Gregg, 1992; Jacobsen et al., 1988; Jenkins \& Burish, 1995).

In this context, the aim of the present study was to assess whether two psychological factors were related to postchemotherapy nausea in cancer patients receiving chemotherapy. The incidence of vomiting was not studied because patients in this study received a new antiemetic drug (Kytril), which drastically reduced this side cffect. The psychological factors considered in our study were: a) anxiety prior to and during the infusion of chemotherapy, which has been linked to postchemotherapy side effects in some studies (Andrykowski \& Gregg, 1992; Jacobsen et al, 1988), and, b) adaptation to cancer: a concept by which we attempt to resume the global psychological state of the patient. Thus, we hypothesized that cancer patients with high levels of anxiety and poor levels of adaptation to illness prior to receiving an infusion of chemotherapy would experience higher intensities of nausca after this treatment, regardless of the drug schedule administered.
Method

\section{Participants}

Participants were patients at a large comprehensive cancer center (Hospital de la Santa Creu i Sant Pau, Barcelona, Spain) and were interviewed between October 1993 and May 1994. Part of a larger study, the results reported here are from 63 patients, 20 men $(31.7 \%)$ and 43 women $(68.3 \%)$, who: a) consented to be interviewed prior to receiving their chemotherapy infusion (see Procedure); b) were receiving the same antiemetic agent (Kytril); and, c) returned a notebook, which they were requested to fill in at home to assess postchemotherapy distress (see Procedure).

Thirty-two patients $(50.8 \%)$ had breast cancer, 10 patients (15.9\%) were treated for sarcoma, 6 patients $(9.5 \%)$ had a diagnosis of lung cancer, 7 patients (11.1\%) had head and neck cancers, and the other 8 patients (12.6\%) had various kinds of cancer (lymphomas, testicular cancer, gynecological cancers). Twenty-eight patients were receiving either the first or second infusions of chemotherapy when interviewed, 19 patiens were receiving infusions three or four, whereas the other 16 patients had received five or more treatment infusions.

The mean age of the patients was 48.43 years $(S D=$ 13.28 years), with a minimum age of 17 years and a maximum age of 70 years.

\section{Measurements}

All measurements were obtained by $10-\mathrm{cm}$ visual analogue scales (VAS). VAS have been widely used to assess symptoms such as anxicty, nausea, or vomiting (Andrykowski \& Gregg, 1992; Bovbjerg et al., 1992; Challis \& Stam, 1992; Jacobsen et al., 1993; Lindley et al., 1992) as well as other psychological aspects (Cimprich, 1992; Mock, 1993), and have been considered an adequate tool to be used with cancer patients (Coscarelli, Heinrich, Aadland, \& Ganz, 1990; Morrow et al., 1992). In our study, anxiety, nausea intensity, and other somatic symptoms, such as pain, sleep disturbances, or sickness were measured using VAS before and after the infusion of chemotherapy. These somatic symptoms were assessed in order to prevent patients from focusing their attention only on nausea and anxiety and, therefore, will not be included in the results. Nausea was assessed by a VAS with the sentences, "Since I received the treatment up to the present, I have not experienced any nausea at all" on the left side, and "Since I received the treatment up to the present, I have experienced intense nausea" on the right side. Anxicty was assessed by a VAS with the sentences, "I have no anxiety at all" and "I feel very anxious now." Patients' answers were rated as 0-100 values (with 0 at the left and 100 at the right side of the VAS). Thus, the higher the rate, the greater the intensity of the symptoms assessed. More comprehensive information about these scales can be found in Blasco (1992). 
When this study began, there was only one instrument available in the Spanish language to assess adaptation to illness: the Adaptation to Cancer Index (Blasco \& Bayés, 1992). This index is derived from a measure of the Quality of Lite, developed by Font (1988), which has becn applicd in some other studies (Juan, Blasco, Font, Pallarés, \& Sanz, 1999; Pallarés et al., 1996). This instrument is a package of 27 VAS, which assesses the disruption caused by illness in various arcas of the patient's life. Disruption is rated on scales ranging from 0 to 100: the higher the rate, the greater the disruption. From this assessment, the Adaptation to Cancer Index assumes "adaptation" to be a relationship between the demands of the illness and the patient's disturbed psychological responses to them. Thus, it assesses the disruption caused by cancer in four areas: somatic symptoms (SYMPT), loss of daily living habits (HABIT), family relationships (FAMREL), and psychological disturbance (PSYCHO). Adaptation is assessed as the ratio between the sum of SYMPT, HABIT, and FAMREL scales, and the PSYCHO scale multiplied by a constant of 3 :

$$
\text { ADAPTATION }=\frac{\text { SYMPT }+ \text { HABIT }+ \text { FAMREL }}{3 \times \text { PSYCHO }}
$$

Using this index, a value of 1 or more means that the patient is adapted, because his or her psychological disturbance is not higher than disruptions in the other areas. On the other hand, values between 0 and I mean that the patient is not adapted, because psychological disturbance is higher than disturbances in the other areas. The authors suggest that the index should be used not as a continuous variable, but as a dichotomous measure to classify patients as either "adapted" or "not adapted."

\section{Procedure}

Patients were asked to participate in the study just before receiving their chemotherapy infusion, and were requested to answer some questions about their general state before and after the infusion. All patients received chemotherapy in an outpatient schedule and were always interviewed by the same two female researchers. Once patients had agreed to participate, the VAS procedure and the general characteristics of the study were explained. Patients answered the questions just before receiving the infusion and were provided with a notebook to take home. This notebook also contained some VAS which assessed: a) the anxiety experienced during the infusion; b) nausea and vomiting after chemotherapy, and c) other somatic side effects such as sickness, sleep disorders, and pain. In the notebook, the patient assessed two 24-hour periods, that is, the day chemotherapy was administered and the day after. Patients received instructions to fill in the notebooks before going to bed on both days. When patients came back to the hospital for the next chemotherapy infusion, they returned the notebook to the researchers. Because two values of nausea intensity were recorded in the notebook, the highest value was always considered the measure of postchemotherapy nausea. Similarly, the highest value of anxiety ("anxiety before receiving the infusion" and "anxiety during the infusion") was considered as the measure of anxicty to be analyzed in the results.

Two groups of chemotherapy schedules were considered according to the ratings by physicians of the Oncology Service Unit (Stam \& Challis, 1989): schedules with high emetogenicity (containing cisplatin), and schedules with moderate emetogenicity (without cisplatin).

\section{Statistical Analyses}

Following the methodology applied by Andrykowski and Gregg (1992) and Jacobsen et al. (1988, 1993, 1995), a multiple regression analysis, using the stepwise method, was performed on the following variables: anxiety level (considered as a continuous variable), adaptation level (considered as a dichotomous variable), emetogenicity level (considered as a dichotomous variable), sex, age, and number of infusions previously received. This analysis was performed with the Statistical Package SPSS 7.5 2S for Windows.

\section{Results}

The analysis indicated that the distribution of one of the independent variables (anxiety) was not normal. Thus, anxiety was dichotomized (with high-anxious patients showing a rate higher or equal to 45 and low-anxious patients showing a rate lower than 45 ). The results confirmed the relationship between nausea intensity and the variables "adaptation level" and "anxiety level," which accounted for $24 \%$ of the variance (multiple $R=.49, F(2,57)=9.25, p=.0003$ ). The remaining variables were not included in the stepwise equation. Thus, patients with higher levels of nausea tended to have higher levels of anxiety $(\beta=333)$ and poorer levels of adaptation $(\beta=-.290)$. The high tolerance value obtained (.938) indicated that the low correlations between variables did not cause multicollinearity. The distribution of the residuals was normal but not random; and they showed homogenous variances. It must be concluded that some other variables that are not included in the analysis could account for the variance of the nausea intensity.

\section{Discussion}

Our results support the hypothesis that psychological factors are related to nausea intensity despite pharmacologic variables. Patients reporting high level of anxiety and/or a poor level of adaptation to illness before receiving chemotherapy experienced higher nausea intensity, regardiess 
of sex, age, drug schedule administered, and number of infusions previously received, although the regression analysis revealed that some other variables, not assessed in our study, account for the variance observed in nausea intensity.

The role of anxiety is not surprising since anxiety seems to be clearly related to emesis in patients receiving chemotherapy (Andrykowski, 1990; Andrykowski \& Gregg, 1992) although its causal role remains unclear (Andrykowski, 1990; Blasco, 1994). Thus, anxiety can be considered both a prognostic factor of increased postchemotherapy side effects and a target symptom to be treated in order to reduce the distress experienced by patients receiving chemotherapy. In fact, Jacobsen, Bovjerg, and Redd (1993) observed anticipatory anxiety states in women receiving chemotherapy. However, anxiety may be an outcome of poor adaptation to cancer, as is discussed below.

Why is poor adaptation to cancer also related to increased levels of postchemotherapy nausea? In our opinion, adaptation to cancer reflects whether or not the patient suffers from a distressed psychological state (depression, subjective health impairment, feelings of anxiety, and fears about illness), which is caused by the experience of illness, and not exclusively by the chemotherapy itself. This emotional state could increase the side effects produced by chemotherapy or, at least, it could worsen an impaired subjective state. This negative modulation is not surprising, since a positive modulation was found in the placebo effect (Lewis, Lewis, \& Tattersfield, 1984) or, more recently, in cancer survival (Fawzy et al., 1993; Spiegel, Bloom, Kraemer, \& Gottheil, 1989). In other words, it implies that psychological factors could modulate postchemotherapy nausea. However, some features of the present study must be pointed out.

Regression analysis indicated that nausea intensity was not completely explained by anxiety and adaptation level. Which other variables could explain nausea? We do not know. Perhaps the heterogenous sample of diagnoses could be responsible of this limitation of our study. This possibility cannot be excluded, but Andrykowski and Gregg (1992) did not use a homogenous sample of diagnoses and found that psychological variables accounted for the $13.5 \%$ of the variance. However, neither Andrykowski and Gregg (1992) nor Jacobsen et al. $(1988,1993,1995)$ specified the accuracy of their analyses of residuals on their regression models, so perhaps their studies had the same limitations of ours.

Our results do not agree with those previously reported by Andrykowski and Gregg (1992), who observed in their regression model that the emetic potential of the chemotherapy schedule accounted for some of the variance of the nausea intensity. This discrepancy may be due to two reasons: a) our consideration of the emetic potential as a dichotomous variable, and, b) our measures of anxiety and nausea intensity, which were not treated as the mean of several measures obtained in a longitudinal study.

On the other hand, we evaluated only certain kinds of patients and chemotherapy schedules. Research with larger samples, using accurate longitudinal studies assessing the whole experience of chemotherapy, is needed to confirm whether anxiety and adaptation to illness are always related to the intensity of postchemotherapy nausea, regardless of the degree of emetogenicity of the chemotherapy schedule administered, and whether this relationship could be a causal one. If this were the case, clinical strategies for the treatment of chemotherapy-induced nausea and vomiting could be applied more accurately. These strategies could be preventive and addressed to managing specific factors that appear just before treatment, such as anxiety or lack of information (Burish, Carey, Krozely, \& Greco, 1987; Burish, Snyder, \& Jenkins, 1991; Jacobsen et al., 1995). However, this prevention could also be achieved by treatments addressing distressful psychological feelings (i.e., fears about the illness, subjective health impairment) that are present along the lifespan of cancer patients receiving long treatments such as chemotherapy. In this case, perhaps a global therapeutic approach, according to the feaures developed by Fawzy, Fawzy, Ardnt, and Pasnau (1995), and Fawzy and Fawzy (1998) based on a structured intervention consisting on health education, stress management/behavioral training, coping including problem-solving techniques, and psychosocial group support, could help patients to avoid postchemotherapy nausea, as well as other negative features associated with the experience of cancer (Hitch, Fielding, \& Llewelyn, 1994; Meyer \& Mark, 1995).

\section{References}

Andrykowski, M.A. (1990). The role of anxiety in the development of anticipatory nausea in cancer chemotherapy: A review and synthesis. Psychosomatic Medicine, 52, 458-475.

Andrykowski, M.A., \& Gregg. M.E. (1992). The role of psychological variables in post-chemotherapy nausea: Anxiety and expectation. Pyschosomatic Medicine, 54, 48-58.

Andrykowski, M.A. Redd, W.H., \& Hatfield, A.K. (1985). Development of anticipatory nausea: A prospective analysis. Journal of Consulting and Clinical Psychology, 53, 447-454.

Blasco, T. (1992) Relación entre pensamientos de molestia y efectos secundarios de la quimioterapia en pacientes de cáncer. Clínica y Salud, 3, 273-279.

Blasco, T. (1994). Anticipatory nausea and vomiting: Are psychological factors adequately investigated? British Joumal of Clintcal Psychology, 33, 85-100.

Blasco, T., \& Bayés, R. (1992). Adaptation to illness in cancer patients: A preliminaty report. European Journal of Psychological Assessment, 8, 207-211.

Bovbjerg, D.H, Redd, W.H., Jacobsen, P.B., Manne, S.L., Taylor, K.L., Surbone, A., Crown, J.P., Norton. L., Gilewski, T.A., Hudis, C.A., Reichman, B.S., Kaufman, R.J., Currie, V.E., \& Hakes, T.B. (1992). An experimental analysis of classically conditioned nausea during cancer chemotherapy. Psychosomatic Medicine, 54, 623-637. 
Burish, T.G., \& Carey, M.P. (1986). Conditioned aversive responses in cancer chemotherapy patients: Theoretical and developmental analysis. Jourtal of Consulting and Clinical Psychology, 54, 593-600.

Burish, T.G., Carey, M.P, Krozely, M.K., \& Greco, F.A. (1987). Conditioned side effects induced by cancer chemotherapy: Prevention through behavioral treatment. Joumal of Consulting and Clinical Psychology, 55, 42-48.

Burish, T.G., Snyder, S.L., \& Jenkins, R.A. (1991). Preparing patients for cancer chemotherapy: Effect of coping preparation and relaxation interventions. Joumal of Consulling and Clinical Psychology, 59, 518-525.

Burish, T.G., \& Tope, D.M. (1992). Psychological techniques for controlling the adverse side effects of cancer chemotherapy: Findings from a decade of research. Journal of Pain and Symptom Management, 7, 287-301.

Carey, M.P., \& Burish, T.G. (1988). Etiology and treatment of the psychological side- effects associated with cancer chemotherapy: A critical review and discussion. Psychological Bulletin, 104, 307-325.

Challis, G.B., \& Stam, H.J. (1992). A longitudinal study of the development of anticipatory nausea and vomiting in cancer chemotherapy patients: The role of absorption and autonomic perception. Health Psychology, 11, 181-189.

Cimprich, B. (1992). Attentional fatigue following breast cancer surgery. Research Nursing and Health, 15, 199-207.

Coates, A. (1986). Coping with cytotoxic therapy. In B.A. Stoll \& B.D. Weisman (Eds.). Coping with cancer stress (pp. 39 44). Dordrecht, Holland: Martinus Nijhoff.

Coscarelli, C.A., Heinrich, R.L., Aadland, R.L., \& Ganz, P.A. (1990). Assessing problems of cancer patients: Psychometric properties of the Cancer Inventory of Problem Situations. Health Psychology, 9, 83-102.

Fawzy, F.I., \& Fawzy N.W. (1998). Group therapy in the cancer setting. Journal of Psychosomatic Research, 45, 191-200.

Fawzy, F.1, Fawzy, N.W., Arndt, L.A., \& Pasnau, R.O. (1995). Critical review of psychosocial interventions in cancer care. Archives of General Psychiarry, 52, 100-113.

Fawzy, F.I., Fawzy, N.W., Hyun, C.S., Elashoff, R., Guthrie, R., Fahey J.L., \& Morton D.L. (1993). Malignant melanoma: Effects of an early structured psychiatric intervention, coping and affective state on recurrence and survival 6 years later. Archives of General Psychiatry, 50, 681-689.

Font, A. (1988). Valoración de la calidad de vida en pacientes de cáncer. Unpublished doctoral dissertation, Universitat Autònoma de Barcelona, Bellaterra, Spain.

Fredrikson, M., Hursti, T., Salmi, P., Johansson, S., Fürst, C.J., Peterson, C., \& Steineck, G. (1993). Conditioned nausea after cancer chemotherapy and autonomic nervous system conditionability. Scandinavian Joumal of Psychology, 34, 318327.

Gralla, R.J. (1987). Antiemetic therapy and cancer chemotherapy. In K. Hellman, D. Phil, \& S. K. Carter (Eds.), Fundamentals of cancer chemotherapy (pp. 387-396). New York: McGraw Hill.
Hitch, P.J., Fielding, R.G., \& Llewelyn, S P. (1994), Effectiveness of self-help and support groups for cancer patients: A review, Psychology and Health, 9, 437-448.

Hursti, T., Fredrikson, M., Börjeson, S., Fürst, C.J., Peterson, C., \& Steineck, G. (1992). Association between personality characteristics and the prevalence and extinction of conditioned nausea after chemotherapy. Journal of Psychosocial Oncology, 10, 59-77.

Hursti, T., Fredrikson, M., Steineck, G., Börjeson, S., Füirst, C.J., \& Peterson, C. (1994). Factors modifying the risk of acute and conditioned nausea and vomiting in ovarian cancer patients. International Joumal of Oncology, 4, 695-701.

Jacobsen, P.B., Andrykowski, M.A., Redd, W.H., Die-Trill, M., Hakes, T.B., Kaufman, R.J,, Currie V., \& Holland, J.C. (1988). Nonpharmacologic factors in the development of posttreatment nausea with adjuvant chemotherapy for breast cancer. Cancer, 61, 379-385.

Jacobsen, P.B., Bovbjerg, D.H., \& Redd, W.H. (1993). Anticipatory anxiety in women receiving chemotherapy for breast cancer. Health Psychology, 12, 469-475.

Jacobsen, P.B., Bovbjerg, D.H., Schwartz, M.D. Andrykowski, M.A., Futterman, A.D., Gilewski, T., Norton, L., \& Redd, W.H. (1993). Formation of food aversions in cancer patients receiving repeated infusions of chemotherapy. Behavior Research and Therapy, 31, 739-748.

Jacobsen, P.B., Bovbjerg, D.H., Schwartz, M.D., Hudis, C.A., Gilewski, T.A., \& Norton, L. (1995). Conditioned emotional distress in women receiving chemotherapy for breast cancer. Journal of Consulting and Clinical Psychology, 63, 108-114.

Jenkins, R.A., \& Burish, T.G. (1995). Health locus of control, chemotherapy nelated distress, and response to behavioral intervention in cancer patients. Psychology and Health, 10, 463-475.

Juan, E., Blasco, T., Font, A., Pallarés, C. \& Sanz, A. (1999) Un nuevo instrumento para valorar la calidad de vida en cáncer de pulmón: estudio preliminar. Oncología, 22, 125-129.

Kvale, G., Hughdal, K., Asbjornsen, A., Rosengren, B., Lote, K., \& Norby, H. (1991). Anticipatory nausea and vomiting in cancer patients. Joumal of Consulting and Clinical Psychology, $59,894-898$.

Kvale, G., Psychol, C., \& Hugdahl, K. (1994). Cardiovascular conditioning and anticipatory nausea and vomiting in cancer patients. Behavioral Medicine, 20, 78-83.

Lewis, R.A., Lewis, M.N., \& Tattersfield, A.E. (1984). Asthma induced by suggestion: Is it due to airway cooling? American Review of Respiratory Diseases, 129, 691-695.

Lindley, C.M., Hirsch, J.D., O'Neill, C.V., Transau, M.C., Gilbert, C.S., \& Osterhaus, J.T. (1992). Quality of life consequences of chemotherapy-induced emesis. Quality of Life Research, I, 331-340.

Love, R.R., Leventhal, H., Easterling, D.V., \& Nerenz, D.R. (1989). Side effects and emotional distress during cancer chemotherapy. Cancer, 63, 604-612

Meyer, T.J., \& Mark, M.M. (1995). Effects of psychosocial interventions with adult cancer patients: A meta-analysis of tandomized experiments. Health Psychology, 14, 101-108. 
Mock, V. (1993). Body image in women treated for breast cancer. Nursing Reseurch, 42, 153-157.

Morrow, G.R., Asbury, R., Hammon, S., Dobkin, P., Caruso, L.1 Pandya, K., \& Rosenthal, S. (1992). Comparing the effectiveness of behavioral treatment for chemotherapy-induced nausea and vomiting when administered by oncologists. oncology nurses, and clinical psychologists. Healh Pswhology. $11,250-256$.

Morrow, G.R., Lindke, J., \& Black, P.M. (1991). Anticipatory nausea development in cancer patients: Replication and extension of a learning model. British Journal of Psychology, $82,61-72$.

Pallarés, C., Maroto, P., Andrés, L., Gómez-Segurı, G. Huidobro, G., Valentí, V. (1996). Relationship between quality of life (QL) and clinical outcome in advanced non-small cell lung cancer (NSCLC): Prospective randomized trial of best supportive carc (BSC) vs. BSC plus chemotherapy (CT). Amols of Oncology, 7, 89-90.

Redd, W.H., Burish. T.G., \& Andrykowski. M.A. (1985). Aversive conditioning and cancer chemotherapy. In T.G. Burish. S.M.
Levy, \& B.E. Meyerowitz (Eds.), Cancer, nutrition and eating bethation: A biobehavioral perspective (pp. 117-132). Hillsilale. $\mathrm{NJ}$ : Erlbaum.

Spiegel, D., Bloom, J.R., Kraemer, H.C., \& Gottheil, E. (1989) Effect of psychosocial treatment on survival of patients with metustatic breast cancer. Lancet, October 74, $888-891$.

Stam, H.J., \& Challis, G.B. (1989). Ratings of cancer chemotherapy toxicity by oncologists, nurses and pharmacists. Joumal of Pain and Symptom Management, 4, 7-12.

Vasterling, J., Jenkins, R.A., Tope, D.M., \& Burish, T.G. (1993). Cognitive distraction and relaxation training for the control of side effects due to cancer chemotherapy. Jom of Behomional Medicine, 76, 65-80.

Watson, M.. \& Marvell, C. (1992). Anticipatory nausea and vomiting annong cancer patients: A review. Psychology and Health, 6,97-106.

Received June 9, 1999 Revision received December 13, 1999 Accepted January 13, 2000 